\title{
PROGRESSION AND IMPACT OF THE FIRST WINTER WAVE OF THE 2009 PANDEMIC H1N1 INFluenza in NeW SOUth Wales, Australia
}

\author{
New South Wales public health network (mcret@doh.health.nsw.gov.au)1 \\ 1. Individual contributors listed as the writing committee at the end of the article
}

This article was published on 22 October 2009.

Citation style for this article: New South Wales public health network. Progression and impact of the first winter wave of the 2009 pandemic H1N1 influenza in New South Wales, Australia. Euro Surveill. 2009;14(42):pii=19365. Available online: http://www.eurosurveillance.org/ViewArticle.aspx?ArticleId=19365

A range of surveillance systems were used to assess the progression and impact of the first wave of pandemic H1N1 influenza in New South Wales, Australia during the southern hemisphere winter. Surveillance methods included laboratory notifications, near realtime emergency department syndromic surveillance, ambulance despatch surveillance, death certificate surveillance and purposebuilt web-based data systems to capture influenza clinic and intensive care unit activity. The epidemic lasted 10 weeks. By 31 August 2009, 1,214 people with pandemic H1N1 influenza infection were hospitalised (17.2 per 100,000 population), 225 were admitted to intensive care (3.2 per 100,000), and 48 died (0.7 per 100,000). Children aged 0-4 years had the highest hospitalisation rates, while adults aged 50-54 had the highest rates of intensive care admission. During the epidemic period, overall presentations to emergency departments were $6 \%$ higher than in 2008, while presentations for influenza-like illness were $736 \%$ higher. At the peak, confirmed cases of pandemic H1N1 influenza consumed $15 \%$ of intensive care capacity. Excess mortality from influenza and pneumonia was lower than in recent influenza seasons. Health services, particularly emergency departments and intensive care units, were substantially affected by the epidemic. Mortality from influenza was comparable with previous seasons.

\section{Introduction}

A pandemic influenza $A(\mathrm{H} 1 \mathrm{~N} 1) v$ - previously called human swine influenza - virus was identified in April 2009 in Mexico and the United States. Since then, widespread community transmission of the virus has been confirmed on all continents, and the World Health Organization has announced a global influenza pandemic [1]. This paper focuses on the pandemic experience of New South Wales (NSW), Australia's most populous state (7.0 million people), which includes Australia's largest city and primary entry port Sydney (4.4 million people).

The first case of pandemic H1N1 influenza was confirmed in Australia on 8 May 2009. A shift in public health response strategy from 'delay' to 'contain' was announced on 22 May, when local community transmission was identified [2]. On 17 June, Australia moved to the 'protect' phase of the response, in recognition of the generally mild clinical characteristics of the virus, and the widespread community transmission in Victoria [3]. This phase focused efforts on early detection and treatment of influenza-like illness in those considered at risk of severe illness. The change to the 'protect' phase saw a shift in laboratory testing from people with appropriate symptoms and potential exposure to the virus to people at greater risk of severe illness, particularly those hospitalised with an influenza-like illness. This shift in testing policy meant that non-laboratory-based surveillance systems became more important in assessing the population and health service impact of the pandemic.

In this report, we provide an overview of the progression and impact of the first winter wave of the 2009 pandemic H1N1 influenza in the Australian context, using data from a range of surveillance systems.

\section{Methods}

We used existing and new surveillance systems to monitor the progress and impact of the pandemic influenza virus. Existing systems included laboratory notifications, the hospital emergency department (ED) [4] and ambulance despatch surveillance system, and death certificate surveillance [5].

\section{Laboratory notifications and hospital admissions}

Public health staff entered information on suspected and confirmed cases and their contacts (including hospital admission status) into an open source, web-based outbreak database system (NetEpi) [6]. All laboratory notifications of confirmed influenza $A(H 1 N 1) v$ were entered centrally into the same database. In addition, eight large public laboratories submitted aggregate information on the number and results of respiratory virus testing performed each week.

Influenza clinics presentations and intensive care unit admissions

Two simple internet-accessible form-based databases were rapidly developed - one for recording daily aggregate influenza clinic activity, and the other for recording daily aggregate influenzarelated intensive care unit activity (total number of suspected or confirmed influenza cases in adults, children and neonates; total number of pregnant patients with suspected or confirmed influenza, and total number of patients requiring treatment with extracorporeal membrane oxygenation [ECMO] for any reason). A separate internetaccessible register was used to collect clinical information on individual patients with confirmed influenza $A$ infection admitted to intensive care $[7,8]$. 


\section{Emergency department presentations}

The ED surveillance system allowed a daily assessment of the number of ED presentations with assigned diagnoses of general respiratory illness, fever, unspecified infections, influenza-like illness and pneumonia. These figures may include some influenza clinic presentations because some hospitals recorded this information in their ED information systems. This was the first time that specialised influenza clinics were provided across the NSW Health service.

The ED surveillance system uses data routinely recorded in ED information systems and transmitted by real-time electronic messaging or frequent batch files to a surveillance database at the NSW Department of Health. This system currently includes 52 public hospital EDs in NSW and covers much of the state's population ( $72 \%$ of the state's 2.4 million annual ED presentations). ED diagnoses saved as International Classification of Diseases versions 9 or 10 [9] or the Systematized Nomenclature of Medicine-Clinical Terms (SNOMED-CT) [10], are used to group ED presentations into 'syndromes', such as influenza-like illness or pneumonia.

\section{Ambulance service activity}

The ambulance surveillance system currently covers the Sydney operations region and uses data recorded by emergency telephone operators who interact with a computer-aided ambulance despatch system. Additions to the despatch database are automatically transmitted in batch files hourly to the Department of Health surveillance database. Ambulance despatches are categorised according to the problem assigned during the emergency call, such as 'breathing problems'.

\section{Deaths}

Death certificate surveillance uses time-series of medical certificate cause of death information from the NSW Registry of Births, Deaths and Marriages to assess all-cause mortality and excess pneumonia and influenza deaths due to circulating influenza viruses.

Risk factors for ICU admission and death included pregnancy and weight status. Pregnancy was defined as any stage of pregnancy and the immediate post-partum period (up to 28 days post-delivery). Obesity was defined as a $\mathrm{BMI} \geq 30 \mathrm{~kg} / \mathrm{m}^{2}$. Morbid obesity was defined as a $\mathrm{BMI} \geq 40 \mathrm{~kg} / \mathrm{m}^{2}$. The week commencing 15 June 2009 was considered the first week of the epidemic, as this corresponded to the first identification of community transmission in NSW. Data was correct and up-to-date as of 29 September 2009.

\section{Results}

\section{Laboratory notifications and hospital admissions}

There was a substantial increase in the number of laboratory tests performed for influenza A during June and July 2009, with a rapid increase in the proportion of positive results. The pandemic influenza $A(H 1 N 1) v$ virus rapidly replaced other circulating strains of influenza $A$ and $B$ (Figure 1 ).

As of 31 August 2009, 5,106 laboratory-confirmed cases of pandemic $\mathrm{H} 1 \mathrm{~N} 1$ influenza were identified in NSW. The median age of cases was 23 years, and $50.2 \%$ were male. Of confirmed cases, 1,214 (17.2 per 100,000) were admitted to hospital. Hospitalised cases tended to be older than other confirmed cases, with a median age of 31 years. Compared to the past five years' influenza seasons there was a shift towards more adults being admitted to hospital with influenza in 2009, particularly in the 50-69 year age group

\section{F I G U R E 1}

Number of positive laboratory tests for influenza for weeks ending 15 May to 4 September 2009, New South Wales, Australia

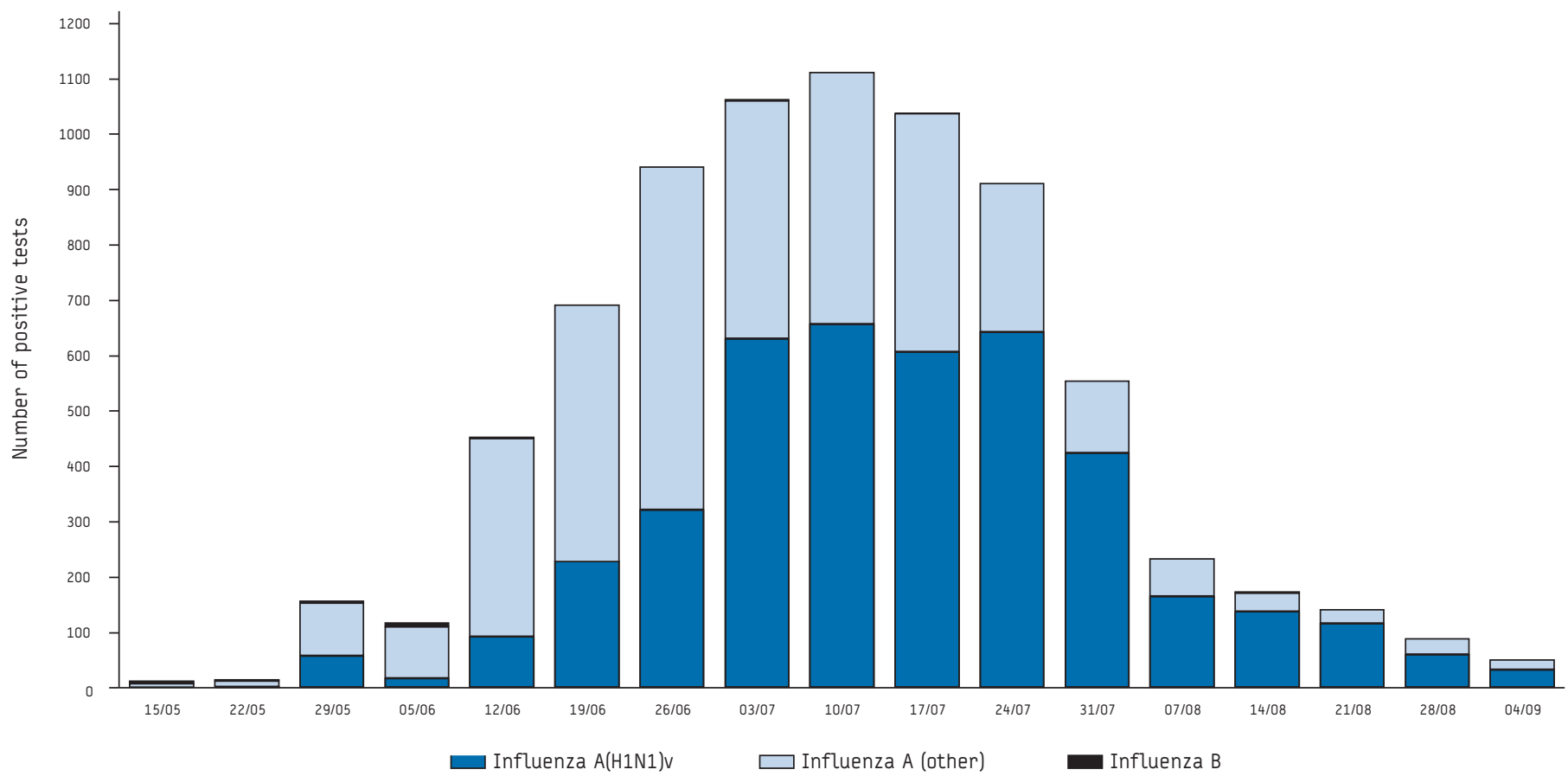

Source: NSW Department of Health 
(data not shown). The median length of stay for those admitted to hospital was four days for adults, three days for children, and four days overall. Children (aged under 16 years) made up $32 \%$ of all confirmed cases admitted to hospital. Children aged 0-4 years old represented the largest proportion of hospital admissions $(21.7 \%$; Table).

The epidemic initially took hold in the metropolitan areas of NSW, particularly in the west and south-western suburbs of Sydney. As community transmission became more established the epidemic spread out in a patchy fashion to regional and rural NSW communities. A broad peak in hospital admissions associated with confirmed pandemic H1N1 influenza occurred during July, but this was partly attributable to regional variation in epidemic progression. The highest rate of hospital admissions related to $\mathrm{H} 1 \mathrm{~N} 1$ influenza was seen in the south-west region of Sydney (25 per 100,000 population), while the lowest rate was seen in the northern Sydney and Central Coast region ( 8 per 100,000). The outbreak lasted approximately 10 weeks (Figure 2 ).

\section{Intensive care unit admissions}

Of those hospitalised, 225 (18.5\%) confirmed cases were admitted to intensive care units (ICUs). The median age of cases admitted to intensive care was 43 years. Of ICU admissions, 197 (87.6\%) were adults aged 16 and older, and 28 (12.4\%) were children. Of children, nine (32\%) were aged 6 months or less. The

\section{T A B L L}

Age distribution and rates of laboratory-confirmed cases of pandemic H1N1 influenza, emergency department presentations, hospital admission, intensive care unit admission and death per 100,000 population with comparison to the general population of New South Wales, Australia, to 31 August 2009

\begin{tabular}{|c|c|c|c|c|c|c|c|c|c|c|c|c|c|c|c|c|c|c|c|}
\hline & \multicolumn{3}{|c|}{$\begin{array}{c}\text { Confirmed cases } \\
\text { of pandemic H1N1 } \\
\text { influenza } \\
\text { (8 May to } 16 \text { June } \\
\text { 2009) }\end{array}$} & \multicolumn{4}{|c|}{$\begin{array}{c}\text { Emergency department } \\
\text { presentations with } \\
\text { influenza- like illness } \\
\text { (17 June to } 31 \text { August } \\
\text { 2009)\# }\end{array}$} & \multicolumn{4}{|c|}{$\begin{array}{l}\text { Hospital admission in } \\
\text { association with confirmed } \\
\text { pandemic H1N1 influenza } \\
\text { infection } \\
\text { (8 May to } 31 \text { August 2009) }\end{array}$} & \multicolumn{4}{|c|}{$\begin{array}{c}\text { Intensive care unit admission } \\
\text { in association with confirmed } \\
\text { pandemic H1N1 influenza infection } \\
\text { (1 June to } 31 \text { August 2009) }\end{array}$} & \multicolumn{4}{|c|}{$\begin{array}{l}\text { Death due to pandemic } \\
\text { H1N1 influenza infection } \\
\text { (8 May to } 31 \text { August 2009) }\end{array}$} \\
\hline & $n$ & $\%$ & $\mathbf{R R}^{\wedge}$ & $\mathrm{n}$ & $\%$ & Rate $^{\wedge \wedge}$ & $\mathrm{RR}^{\wedge}$ & $\mathrm{n}$ & $\%$ & Rate^^ & $\mathrm{RR}^{\wedge}$ & $n$ & $\%$ & Rate $^{\wedge \wedge}$ & $\mathrm{RR}^{\wedge}$ & $\mathrm{n}$ & $\%$ & Rate $^{\wedge \wedge}$ & $\mathrm{RR}^{\wedge}$ \\
\hline \multicolumn{20}{|l|}{ Age group } \\
\hline $0-4$ & 26 & 6.6 & 1 & 779 & 10.3 & 167.5 & 1.6 & 263 & 21.7 & 56.6 & 3.3 & 17 & 7.6 & 3.7 & 1.1 & 0 & 0.0 & 0.0 & 0.0 \\
\hline $5-9$ & 40 & 10.2 & 1.6 & 598 & 7.9 & 137.2 & 1.3 & 69 & 5.7 & 15.8 & 0.9 & 7 & 3.1 & 1.6 & 0.5 & 1 & 2.1 & 0.2 & 0.3 \\
\hline $10-14$ & 44 & 11.2 & 1.7 & 555 & 7.3 & 121.7 & 1.1 & 44 & 3.6 & 9.6 & 0.6 & 2 & 0.9 & 0.4 & 0.1 & 0 & 0.0 & 0.0 & 0.0 \\
\hline $15-19$ & 36 & 9.2 & 1.4 & 867 & 11.4 & 184.1 & 1.7 & 64 & 5.3 & 13.6 & 0.8 & 8 & 3.6 & 1.7 & 0.5 & 0 & 0.0 & 0.0 & 0.0 \\
\hline $20-24$ & 57 & 14.5 & 2.1 & 1015 & 13.4 & 207.9 & 1.9 & 78 & 6.4 & 16.0 & 0.9 & 10 & 4.4 & 2.0 & 0.6 & 1 & 2.1 & 0.2 & 0.3 \\
\hline $25-29$ & 51 & 13 & 1.9 & 870 & 11.5 & 177.3 & 1.6 & 75 & 6.2 & 15.3 & 0.9 & 15 & 6.7 & 3.1 & 1.0 & 2 & 4.2 & 0.4 & 0.6 \\
\hline $30-34$ & 33 & 8.4 & 1.2 & 601 & 7.9 & 123.7 & 1.2 & 72 & 5.9 & 14.8 & 0.9 & 15 & 6.7 & 3.1 & 1.0 & 0 & 0.0 & 0.0 & 0.0 \\
\hline $35-39$ & 29 & 7.4 & 1.0 & 541 & 7.1 & 105.7 & 1.0 & 68 & 5.6 & 13.3 & 0.8 & 23 & 10.2 & 4.5 & 1.4 & 1 & 2.1 & 0.2 & 0.3 \\
\hline $40-44$ & 21 & 5.3 & 0.8 & 414 & 5.5 & 84.0 & 0.8 & 68 & 5.6 & 13.8 & 0.8 & 22 & 9.8 & 4.5 & 1.4 & 5 & 10.4 & 1.0 & 1.5 \\
\hline 45-49 & 23 & 5.9 & 0.8 & 381 & 5.0 & 76.4 & 0.7 & 65 & 5.4 & 13.0 & 0.8 & 13 & 5.8 & 2.6 & 0.8 & 3 & 6.3 & 0.6 & 0.9 \\
\hline 50-54 & 17 & 4.3 & 0.7 & 329 & 4.3 & 70.2 & 0.7 & 103 & 8.5 & 22.0 & 1.3 & 29 & 12.9 & 6.2 & 1.9 & 3 & 6.3 & 0.6 & 0.9 \\
\hline 55-59 & 4 & 1 & 0.2 & 212 & 2.8 & 50.5 & 0.5 & 87 & 7.1 & 20.7 & 1.2 & 20 & 8.9 & 4.8 & 1.5 & 13 & 27.1 & 3.1 & 4.5 \\
\hline $60-64$ & 7 & 1.8 & 0.3 & 146 & 1.9 & 38.2 & 0.4 & 41 & 3.4 & 10.7 & 0.6 & 14 & 6.2 & 3.7 & 1.1 & 5 & 10.4 & 1.3 & 1.9 \\
\hline 65 and over & 4 & 1 & 0.1 & 272 & 3.6 & 27.7 & 0.3 & 115 & 9.5 & 11.7 & 0.7 & 30 & 13.4 & 3.0 & 1.0 & 14 & 29.2 & 1.4 & 2.1 \\
\hline $\begin{array}{l}\text { Total } \\
\text { ( } 95 \% \text { Conf } \\
\text { Interval) }\end{array}$ & 393 & 100 & 1.0 & 7580 & 100 & $\begin{array}{c}107.5 \\
\left(105.1^{-}\right. \\
109.9)\end{array}$ & 1.0 & 1214 & 100.0 & $\begin{array}{c}17.2 \\
(16.2- \\
18.2)\end{array}$ & 1.0 & 225 & 100 & $\begin{array}{c}3.2 \\
(2.8- \\
3.6)\end{array}$ & 1.0 & 48 & 100.0 & $\begin{array}{c}0.7 \\
(0.5- \\
0.9)\end{array}$ & 1.0 \\
\hline \multicolumn{20}{|l|}{ Sex } \\
\hline Male & 201 & 51.1 & 1.0 & 3587 & 47.3 & 102.7 & 1.0 & 601 & 49.5 & 17.2 & 1.0 & 105 & 46.7 & 3.0 & 0.9 & 32 & 66.7 & 0.9 & 1.3 \\
\hline Female & 188 & 47.8 & 0.9 & 3993 & 52.7 & 112.2 & 1.0 & 606 & 50.0 & 17.0 & 1.0 & 120 & 53.3 & 3.4 & 1.1 & 16 & 33.3 & 0.4 & 0.7 \\
\hline \multicolumn{20}{|l|}{ Risk factors } \\
\hline Aboriginal $^{\star \star}$ & -- & & & 246 & 3.6 & 160.3 & 1.6 & 96 & 7.9 & 62.6 & 3.6 & 14 & 6.9 & 9.1 & 3.1 & 5 & 10.4 & 3.3 & 4.7 \\
\hline Pregnancy* & -- & & & -- & & & & -- & & & & 16 & 28.5 & 22.2 & 5.8 & 1 & 50.0 & 1.4 & 10.2 \\
\hline $\begin{array}{l}\text { Obesity } \dagger \\
\left(\geq 30 \mathrm{~kg} / \mathrm{m}^{2}\right)\end{array}$ & -- & & & -- & & & & -- & & & & 73 & 44.0 & 4.1 & 1.7 & 7 & 14.9 & 0.4 & 0.6 \\
\hline $\begin{array}{l}\text { Morbid } \\
\text { obesity } \dagger \\
\left(\geq 40 \mathrm{~kg} / \mathrm{m}^{2}\right)\end{array}$ & -- & & & -- & & & & -- & & & & 24 & 14.5 & 11.4 & 4.7 & 4 & 8.5 & 1.9 & 2.7 \\
\hline $\begin{array}{l}\text { No identified } \\
\text { risk factors }\end{array}$ & -- & & & -- & & & & -- & & & & 23 & 10.2 & & & 5 & 10.4 & & \\
\hline
\end{tabular}

Source: NSW Department of Health and ANZIC Research Centre, Melbourne.

* Pregnancy includes pregnancy and the immediate post-partum period (the 28 days post-delivery). The risk in pregnant women was compared to the population of child-bearing age women (women aged 15-44 years).

**Aboriginal includes Aboriginal and Torres Strait Islander people

† In adults only, compared to the adult population

$\wedge$ Relative risk calculated by comparison with the general NSW population. Source: ABS population estimates (HOIST), Centre for Epidemiology and Research, NSW Department of Health

$\wedge \wedge$ Rate per 100,000 population per period to which the column relates

\# Does not include presentations to NSW public hospital influenza clinics located outside emergency departments 
age distribution of those admitted to hospital differed substantially from those admitted to intensive care (Table). The median length of stay in intensive care was eight days for adults, four days for children, and seven days overall.

NSW public hospitals have 310 ventilated ICU beds for adults (5.5 per 100,000 adult population). At the peak, adult cases admitted to intensive care with confirmed H1N1 influenza occupied $15 \%$ of adult intensive care capacity, and cases admitted to intensive care units with confirmed influenza A (unsubtyped) or suspected influenza-related illness occupied an additional 15\% of ICU capacity, together accounting for around 30\% of adult intensive care unit capacity in NSW public hospitals. The demand for intensive care unit beds was sustained for a number of weeks after the overall level of influenza in NSW had started to decrease (Figure 3). Half of the patients admitted to intensive care required admission within one day of presentation to hospital. Of the 205 patients admitted to intensive care for whom risk factor information was available, 23 (10\%) had no identifiable risk factor for severe illness.

Of patients admitted to intensive care, 159 (70.6\%) required assistance with ventilation, 125 (55.6\%) required invasive mechanical ventilation, and 27 (12\%) required extracorporeal membrane oxygenation (ECMO). The majority (97\%) of patients requiring $\mathrm{ECMO}$ were adults. The length of stay in intensive care for those who required invasive mechanical ventilation was 12 days, while those who required ECMO spent a median of 30 days in intensive care. Of patients admitted to intensive care, 26 (11.6\%) required inter-ICU transfer due to the severity of their illness. Those at increased risk of admission to intensive care or death included pregnant women, Aboriginal and Torres Strait Islander people, and morbidly obese adults (Table).

\section{Influenza clinics}

NSW public hospitals set up influenza clinics to provide rapid assessment and management of patients presenting with influenzalike illness who did not require emergency medical attention. At the peak of the epidemic, NSW influenza clinics were assessing 300 patients per day. Of these patients, around $24 \%$ were provided with free anti-influenza medication, and $19 \%$ were referred to an emergency department for further assessment.

\section{Emergency department presentations}

From 22 May to 3 September 2009, there were 528,654 presentations to the 52 NSW hospitals participating in the ED surveillance system. This was $31,415(6.3 \%)$ more than in the same period in 2008. The number of presentations in school-aged children 5-16 years old increased the most (10\% higher than in the same period in 2008), followed by $17-34$ year-olds ( $8 \%$ ), $0-4$ year-olds (7\%), 35-64 year-olds (7\%) and those aged 65 years or more $(1 \%)$. Over the same 15 -week period, 128,865 patients presenting to these EDs were admitted to hospital; 2,570 (2.0\%) more than in 2008.

For the 49 EDs with good diagnosis completeness in 20082009 , there were 90,305 presentations assigned a respiratory or 'unspecified infection' ED diagnosis over the same period. This was 19,519 (28\%) more than in 2008 . Within the respiratory category, 14,635 presentations were assigned a diagnosis of pneumonia or

F I G U R E 2

Patients with confirmed pandemic H1N1 influenza who were admitted to hospital or intensive care unit or who died, by date of hospital admission, intensive care unit admission or death, 22 May to 31 August 2009, New South Wales, Australia

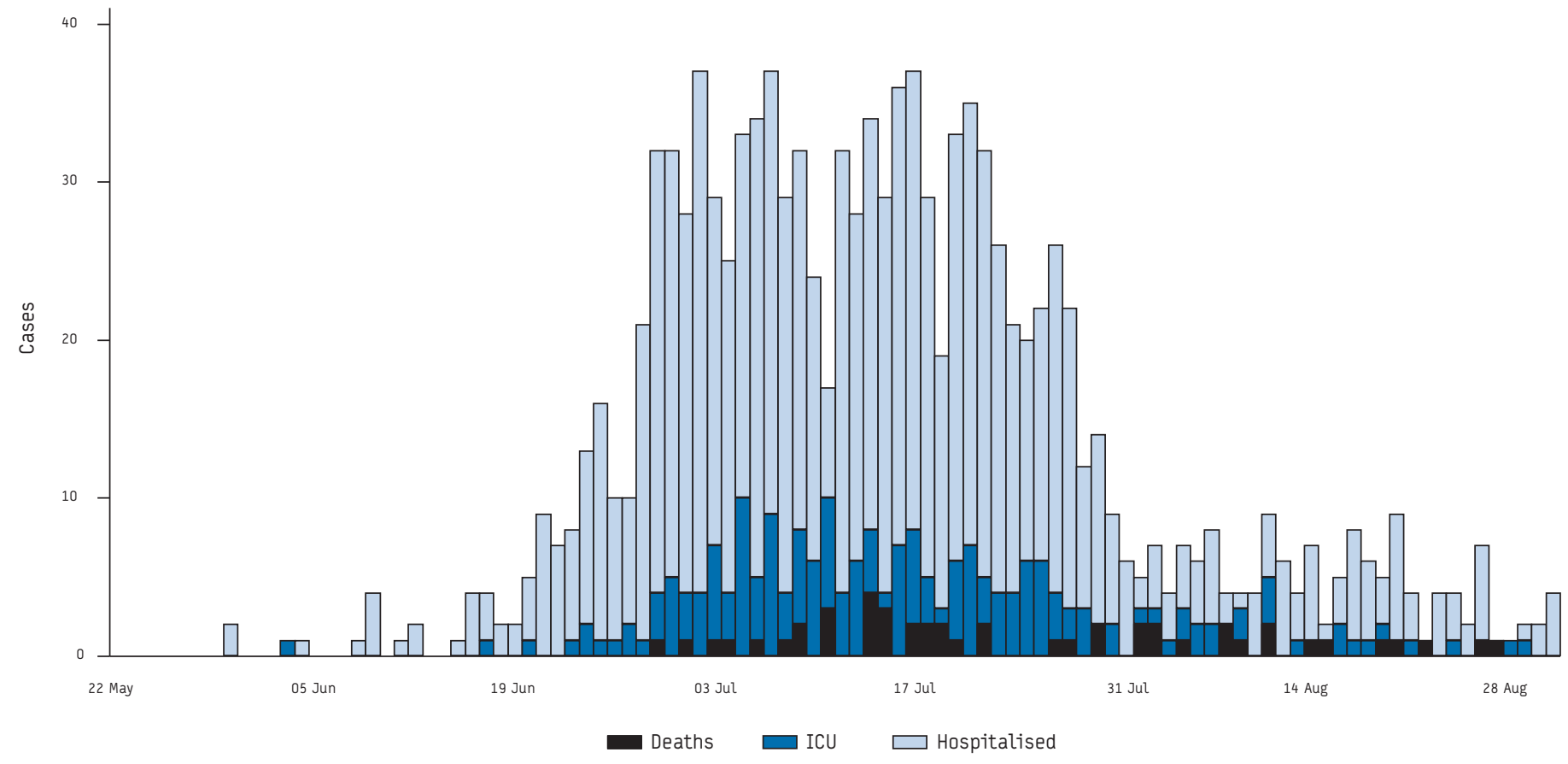

Source: NSW Department of Health and ANZIC Research Centre, Melbourne

Note: Patients who were admitted to an intensive care unit are represented twice, and patients who were admitted to intensive care and died are represented three times. 
influenza-like illness combined, 6,987 (110\%) more than 2008. There were 8,997 presentations in the influenza-like illness category alone, 7,921 (736\%) more than in 2008.

During the four weeks of greatest influenza-related activity from 1 July 2009, the proportion of patients with influenza-like illness admitted to hospital was $6.7 \%$. This compares with $5.6 \%$ for the same period in the previous five years. The weekly peak in overall presentations to the 52 EDs occurred in the week ending 4 July 2009, with 40,597 presentations, 7,448 (22.5\%) above the same week in 2008. Again, presentations in school-aged children $5-16$ years old increased the most ( $58 \%$ higher), followed by $0-4$ year-olds (26\%), $17-34$ year-olds (24\%), 35-64 year-olds (16\%) and those aged 65 years or more (5\%). In the same week, there were 8,608 respiratory and unspecified infection presentations to $49 \mathrm{EDs}$, almost double ( $94 \%$ above) the same week in 2008, while 1,486 presentations were assigned a diagnosis of influenzalike illness or pneumonia combined (a 256\% increase) and 977 presentations were assigned a diagnosis of influenza-like illness alone $(2,405 \%$ increase; Figure 4$)$.

\section{Ambulance service activity}

There was a clearly defined rise in ambulance activity above seasonally expected levels over a one-month period starting in the last week of June (data not shown). As for EDs, the peak in overall excess ambulance activity occurred in the week ending 4 July

F I G U R E 3

Daily aggregate counts of patients with suspected or confirmed influenza admitted to intensive care units, 14 July to 31 August 2009, New South Wales, Australia
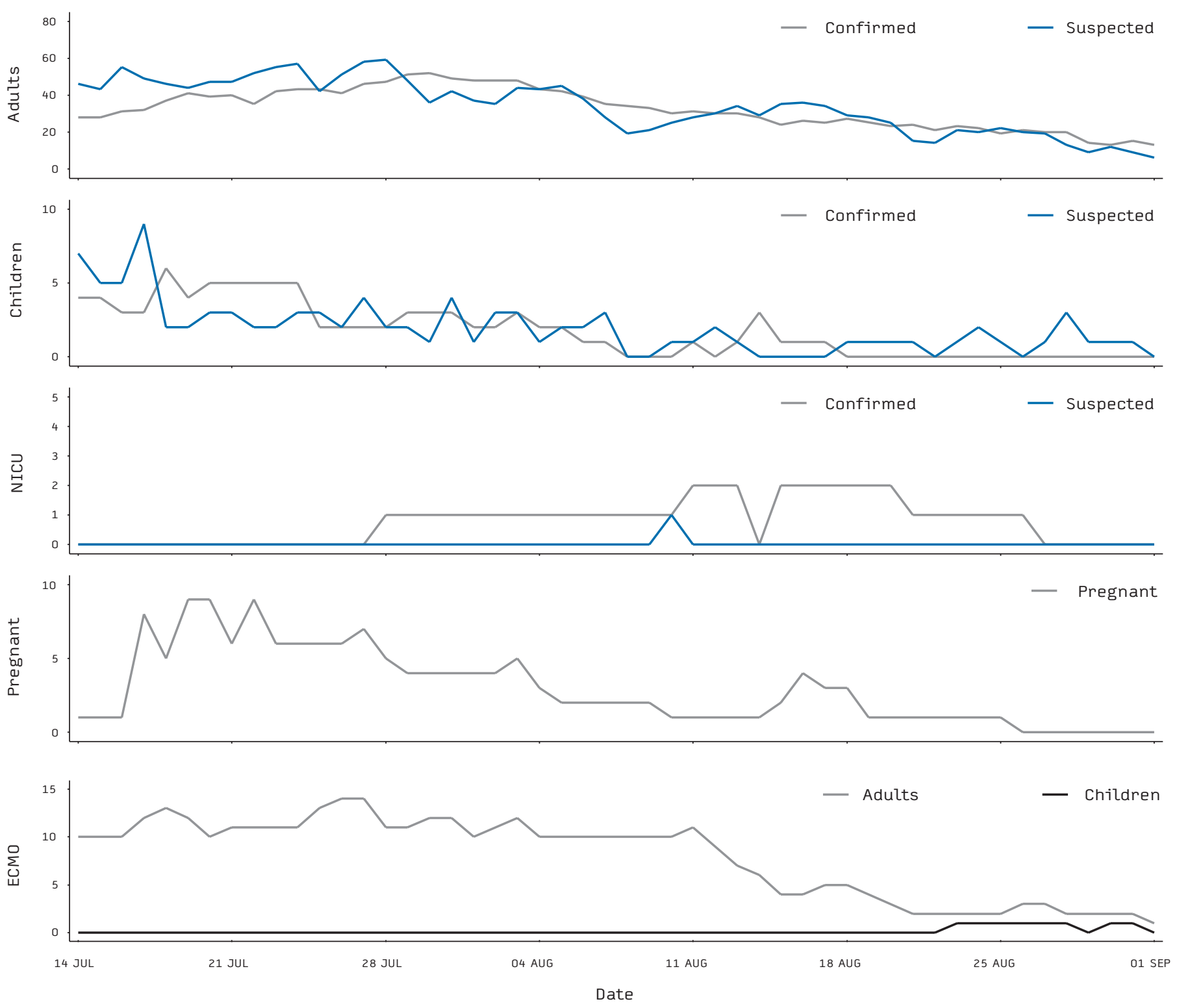
2009. In that week there were 7,480 calls, 853 (13\%) more than in the same week in 2008. In the same week, there were 1,295 calls for breathing problems, 466 (56\%) more than in the same week in 2008. Other problem categories that clearly increased

\section{F I G U R E 4}

Weekly Emergency Department presentations and resulting inpatient admissions in the 12 months from 8 September 2008 to 31 August 2009, compared with the same period in each of the seasons from 2003-4 to 2007-8*, by category, New South Wales, Australia

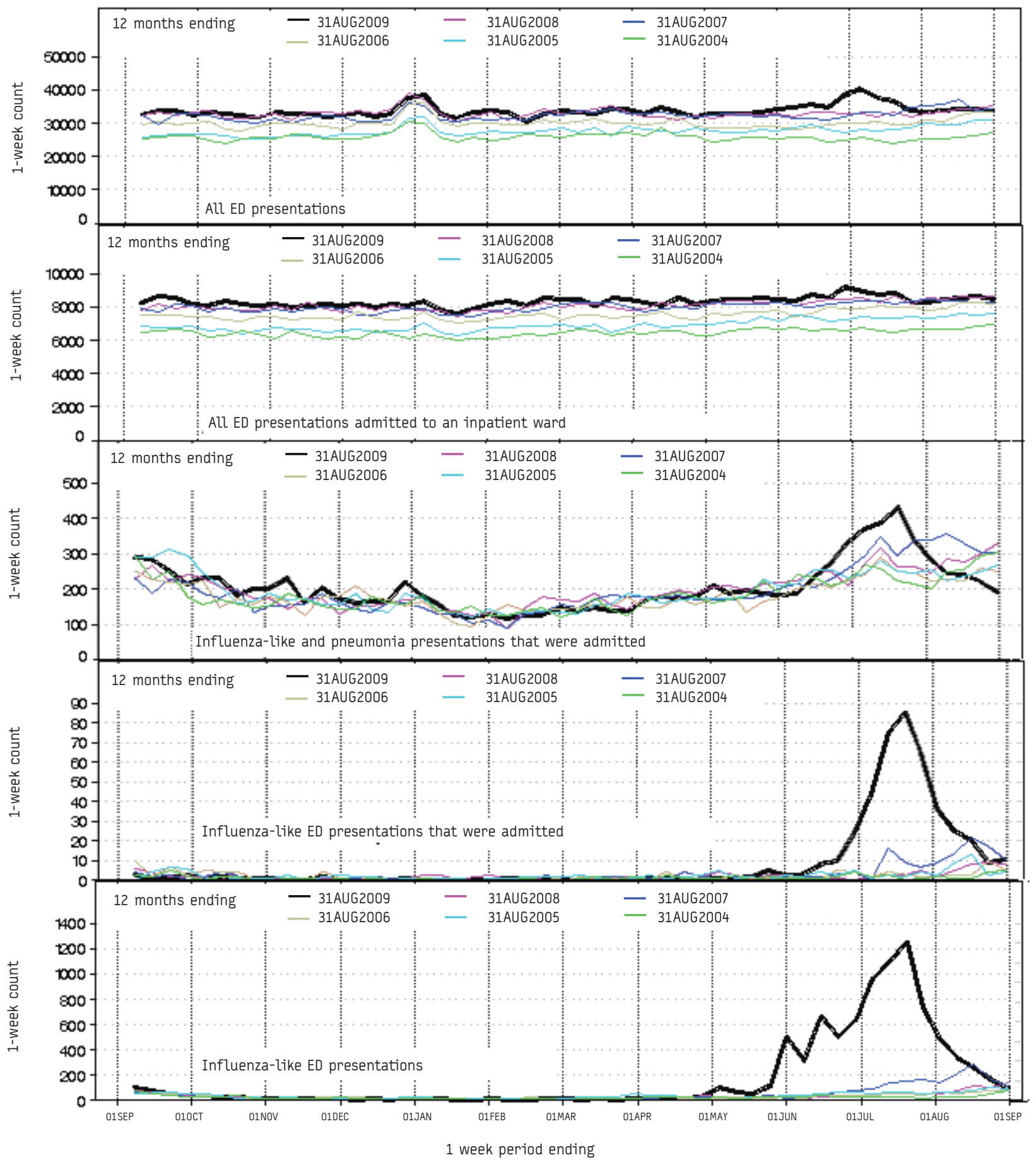

Source: NSW Department of Health

* Some people presenting to New South Wales (NSW) emergency departments (ED) were referred to an influenza clinic without being recorded in the regular ED information system. Influenza-like and pneumonia presentations based on ED diagnosis. Includes 52 hospitals for all presentations and admissions, and 43 hospitals for influenza and pneumonia categories due to limited diagnosis completeness for some hospitals over the 6 years. 
over the same period were 'headache', 'person ill', 'unconscious/ fainting', 'fitting/convulsions' (particularly 0-4 year-olds), and 'chest pain'.

\section{Deaths}

By 31 August 2009, 48 people aged between 9 and 85 years had died in NSW of complications associated with pandemic H1N1 influenza (47 adults and 1 child). The median age of those who died was 58 years. Of those who died, $88.5 \%$ had a chronic underlying condition, while five (10\%) had no risk factor identified. Chronic lung disease (33\%), chronic cardiovascular disease (23\%) and asthma (17\%) were the most common underlying conditions in those who died. Five deaths were in Aboriginal or Torres Strait Islander people (Table).

The impact of the epidemic was comparable to previous seasonal influenza epidemics in terms of deaths due to influenza and pneumonia (Figure 5). Similarly, the impact on all cause mortality was comparable to normal seasonal effects (data not shown).

The impact of the epidemic was lower than in recent influenza seasons, with the weekly proportion of deaths recording influenza or pneumonia on the death certificate remaining markedly lower than the seasonal threshold of excess activity (Figure 5). Similarly, weekly counts of all-cause mortality remained well below several seasonal peaks of recent years (data not shown).

\section{Discussion}

\section{Summary}

The onset of community transmission of pandemic H1N1 influenza at the beginning of winter resulted in a well-defined influenza epidemic in New South Wales. The epidemic lasted 10 weeks. The most notable features of this epidemic were the rapid establishment of community transmission, geographic variability in incidence of hospitalisation, brief and moderately severe capacity problems in emergency departments, more severe and sustained capacity problems in intensive care units, an increased risk of severe illness in those aged between 35 and 60 years, no evidence of greater overall or influenza or pneumonia-related mortality compared to previous influenza seasons, and abrupt cessation of community transmission. The increased demand for intensive care during the epidemic led to postponement of elective surgery in many public hospitals.

\section{Progression and impact}

The first case of pandemic influenza in New South Wales was detected in a traveller returning from overseas on 21 May. Casebased detection and containment efforts were overwhelmed in some urban areas of Sydney by the second week of June. Week one of the epidemic in New South Wales commenced on June 15 , while emergency department activity peaked in early to midJuly - weeks 3 and 4 of the epidemic. The peak in influenzalike ED presentations and hospital admissions for influenza and pneumonia was around four weeks earlier than usual influenza

F I G U R E 5

Weekly rate of deaths attributed to influenza or pneumonia per 1,000 deaths during 2004-2009, to 4 September 2009 , by week of death, New South Wales, Australia

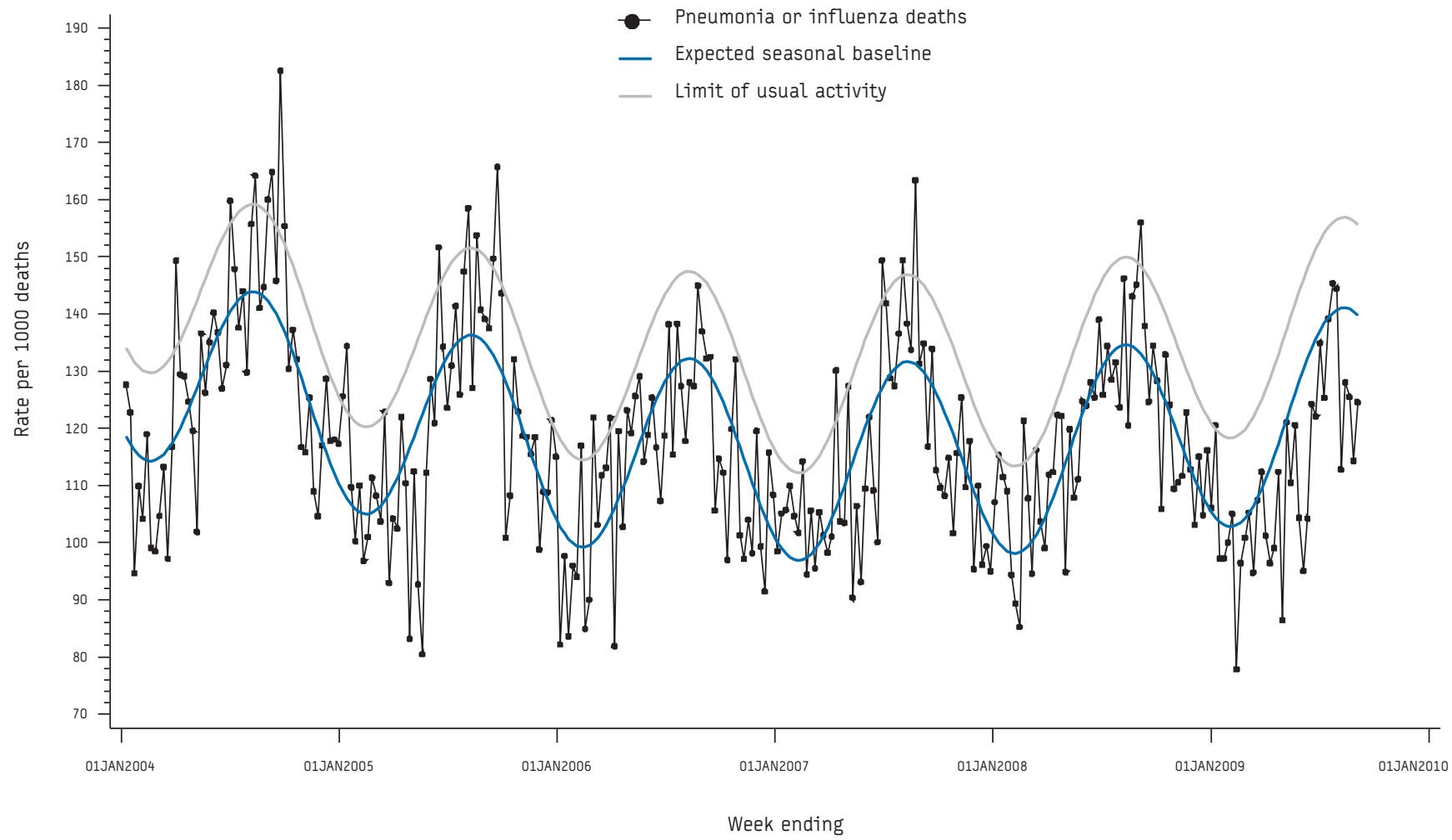

Source: NSW Registry of Births, Deaths and Marriages and Health Outcomes and Information Statistical Toolkit (HOIST), NSW Department of Health Note: includes deaths registered as at 29 September 2009 
seasons. There was a rapid return to normal seasonal activity levels by the beginning of September.

Overall presentations to EDs during the epidemic period were around $6 \%$ higher than in the same period in 2008. Intensive care units were more severely affected. The peak number of suspected and confirmed cases occupying adult intensive care beds peaked at around $15 \%$ of capacity in late July, placing considerable strain on ICU resources and requiring additional investments in high-end ventilators and ECMO machines. The epidemic created substantially increased demand for medical retrieval as well as difficulties transporting those with critical illness who required ECMO. Half of the patients admitted to intensive care required admission within one day of presentation to hospital, while $12 \%$ required inter-ICU transfer due to the severity of their illness.

\section{Geographic spread}

Emergency department surveillance and notifications of laboratory-confirmed patients admitted to hospital provided a guide to the geographic spread of the epidemic. Hospital admission rates varied at least three-fold over health service administrative regions, and up to 50-fold between smaller local government areas. This is likely to reflect real variation rather than variation in intensity of testing, given the general concordance of emergency department, hospital admission and ICU admission surveillance data and the unified administrative arrangements for all public hospitals in NSW, which receive almost all acute admissions. Heterogeneous spread of activity did assist health services to cope by allowing transfers of critically ill patients from highly affected areas to those areas that remained relatively unaffected.

\section{Persons affected}

Rates of hospital admission were highest in children less than five years old, and lowest in 10-14-year-olds. The average length of stay of children was three days, and only $12 \%$ were admitted to intensive care. This is generally consistent with the majority of children having relatively uncomplicated hospital stays. Only one child with a compromised respiratory system was identified to have died from H1N1-related illness.

Almost one quarter of adults aged 20-59 years admitted to hospital were admitted to intensive care and they accounted for approximately two thirds of intensive care admissions overall. Agespecific rates of admission to hospital and intensive care peaked in the 50-54 year age group. Death rates peaked in 55-59-year-olds. The main identifiable risk factors for death were chronic respiratory disease, pregnancy, Aboriginal or Torres Strait Islander status and morbid obesity. Pregnant women experienced the greatest relative increase in risk of severe illness or death. Over $10 \%$ of patients with confirmed H1N1-related illness admitted to intensive care required ECMO due to severe respiratory failure, while $10 \%$ of adult patients admitted to intensive care were healthy individuals with no identifiable risk factors.

Compared with other age groups, adults aged 60 years and over had lower rates of hospital admission, average rates of admission to intensive care (approximately half that of 50-54-year-olds), and above average rates of death associated with pandemic H1N1 influenza.

Overall there were only a small number of H1N1-related deaths in confirmed cases. This was supported by indirect information derived from death certificate surveillance, which indicated that influenza-related excess mortality was relatively low compared with seasonal activity in most recent years. Since most seasonal deaths from influenza and pneumonia occur in the elderly, [5] this finding is consistent with the relatively low level of H1N1 activity seen in the elderly through other surveillance systems. This data suggests that older population groups were largely protected, while some younger people, especially middle-aged adults and pregnant women were severely affected.

\section{Limitations}

The relatively mild clinical profile of most cases of influenza and the change in testing policy at the start of the 'protect' phase means that most cases of influenza in the community are not represented in our data. However, as influenza is a notifiable disease in NSW, and all pandemic H1N1 influenza notifications were entered into one database, the reporting of confirmed cases is likely to be almost $100 \%$ complete.

Ascertainment of all hospitalised cases is likely to be less than complete despite intensive testing of patients admitted to hospitals and intensive care units. Firstly, it is important to note that the sensitivity of the PCR test for pandemic influenza $A(H 1 N 1) v$ may be less than $100 \%$, and is dependent on timely and high quality specimen collection, which may not have been possible for all patients [11]. We know that counts of cases of clinically suspected influenza-related illness in intensive care units tracked at the same levels as cases of confirmed H1N1-related illness, therefore the impact of influenza $A(\mathrm{H} 1 \mathrm{~N} 1) \mathrm{v}$ on intensive care capacity may be under-estimated. Secondly, the level of case ascertainment for hospitalised patients could not be cross-checked with the NSW public hospital inpatient records at the time of writing, as these records usually take some months to be coded and reported. Finally, data collection was censored as of 29 September 2009, which means that information relating to the period to 31 August may be incomplete. Further investigation of the level of H1N1 case ascertainment, in particular ascertainment in intensive care units is warranted.

While it is possible that public health messages which encouraged patients to seek medical help at emergency departments during the containment phase were partly responsible for the increased level of emergency department presentations for influenza-like illness seen at this time, during the 'protect' phase patients with influenza-like illness who were at risk of severe disease were encouraged to present early to their local general practitioner rather than the emergency department. Some patients may have attended emergency departments regardless; however the proportion requiring admission to hospital during July was higher than in previous influenza seasons. This indicates that increased community anxiety was probably not a major factor driving the increased number of presentations to emergency departments during the peak of the epidemic.

Information on the population seroconversion rate and clinical attack rate is not yet available. Seroprevalence data could provide direct support for our inferences from hospital admission data that transmission in optimal winter conditions has been patchy, and will be important to explain the varying rate of illness observed in different age groups.

\section{Conclusion}

NSW experienced a well-defined epidemic of influenza $A(H 1 N 1) v$ during the winter of 2009. This epidemic had a substantial impact on public health, emergency department and intensive care services, but influenza-related mortality and 
overall mortality was lower than during several recent influenza seasons. Particular features of the epidemic included the severity of respiratory failure in some adult patients who required admission to intensive care, and the increased risk of severe illness in pregnant women.

\section{Acknowledgements}

We acknowledge the work of the NSW public health network staff who contributed long hours and performed painstaking data collection to support the public health response to pandemic H1N1 influenza. We thank the staff of the NSW Department of Health and NSW public hospitals who contributed to the surveillance systems and data collection, and the Australian and New Zealand Intensive Care Research Centre (ANZIC-RC) of Monash University, Melbourne for the development of the intensive care H1N1 register and coordination of the intensive care data collection.

\section{Writing committee}

Cretikos $\mathrm{MA}^{1,2}$, Muscatello $\mathrm{DJ}^{1,3}$, Patterson $\mathrm{J}^{1}$, Conaty $\mathrm{S}^{4}$, Churches $\mathrm{T}^{1}$, Fizzell $\mathrm{J}^{1}$, Chant $\mathrm{KG}^{1}$, McAnulty $\mathrm{JM}^{1}$, Thackway $\mathrm{S}^{1}$

1. NSW Department of Health, Sydney, New South Wales, Australia

2. School of Public Health, The University of Sydney, Sydney, New South Wales, Australia

3. School of Public Health and Community Medicine, University of New South Wales, Australia

4. Sydney South West Area Health Service, New South Wales, Australia

\section{References}

1. World Health Organization. Pandemic (H1N1) 2009 - update 62 (revised 21 August 2009). 2009 [accessed 29 September 2009]. Available from: http://www.who. int/csr/don/2009_08_21/en/index.html

2. Australian Government Department of Health and Ageing. Alert level raised to 'contain'. 2009 [accessed 29 September 2009]. Available from: http://www. healthemergency.gov.au/internet/healthemergency/publishing.nsf/Content/ news-022

3. Australian Government Department of Health and Ageing. New pandemic phase 'protect'. 2009 [accessed 29 September 2009]. Available from: http://www. healthemergency.gov.au/internet/healthemergency/publishing.nsf/Content/ news-170609

4. Muscatello DJ, Churches T, Kaldor J, Zheng W, Chiu C, Correll P, et al. An automated, broad-based, near real-time public health surveillance system using presentations to hospital Emergency Departments in New South Wales, Australia. BMC Public Health. 2005;5:141.

5. Muscatello DJ, Morton PM, Evans I, Gilmour R. Prospective surveillance of excess mortality due to influenza in New South Wales: feasibility and statistical approach. Commun Dis Intell. 2008;32(4):435-42.

6. NSW Department of Health. NetEpi Collection: free, open source, networkenabled tools for epidemiology and public health practice. 2009 [accessed 29 September 2009]. Available from: http://code.google.com/p/netepi/

7. Jones DA, Cooper DJ, Finfer SR, Bellomo R, Myburgh JA, Higgins A, et al. Advancing intensive care research in Australia and New Zealand: development of the binational ANZIC Research Centre. Crit Care Resusc. 2007;9(2):198-204.

8. Anderson TA, Hart GK, Kainer MA; ANZICS Database Management Committee. Pandemic influenza-implications for critical care resources in Australia and New Zealand. J Crit Care. 2003;18(3):173-80.

9. World Health Organization [Internet]. International Classification of Diseases (ICD). Available from: http://www.who.int/classifications/icd/en/

10. International Health Terminology Standards Development Organisation [Internet]. Systematized Nomenclature of Medicine-Clinical Terms (SNOMED CT). Available from: http://www.ihtsdo.org/about-ihtsdo/

11. Dwyer DE, Smith DW, Catton MG, Barr IG. Laboratory diagnosis of human seasonal and pandemic influenza virus infection. Med J Aust. 2006;185(10 Suppl):S48-53. 